\title{
MENINGKATKAN TEKNIK DASAR LEMPAR CAKRAM DALAM PROSES BELAJAR MENGAJARDENGAN MENGGUNAKAN MEDIA MODIFIKASI
}

\author{
Candra Cahyono \\ PJKR FKIP UNIB, e-mail:candraganteng3@gmail.com \\ Yarmani \\ Universitas Bengkulu \\ Arwin \\ Universitas Bengkulu
}

\begin{abstract}
Abstrak
Penelitian ini bertujuan untuk meningkatkan teknik dasar lempar cakram dalam proses belajar mengajar dengan mengunakan media modifikasi pada siswa kelas V B SD Negeri 18 Kota Bengkulu. Penelitian ini adalah penelitian tindakan kelas (classroom action research). Subjek penelitian siswa kelas V B SD Negeri 18 Kota Bengkulu yang berjumlah 25 siswa. Hasil pra siklus dalam proses belajar mengajar teknik dasar lempar cakram secara keseluruhan terdapat $20 \%$ tuntas belajar dan $80 \%$ belum tuntas belajar. Dan hasil penelitian pada siklus kesatu menunjukan bahwa jumlah indikator pada lembar observasi aktivitas guru dalam pembelajaran masih terlaksana 18 item atau baru mendapat presentase (72\%), dan pada lembar observasi aktivitas belajar siswa pada pembelajaran masih terlaksana 13 item atau baru mendapat presentase (52\%) dari jumlah keseluruhan lembar observasi yaitu 25 item. Ini menunjukan bahwa proses belajar mengajar baik guru maupun siswa masih rendah atau masih pada kategori belum tuntas belajar. Sedangkan hasil disiklus ke dua menunjukan bahwa jumlah indikator yang guru lakukan pada proses belajar mengajar meningkat yaitu 22 item atau mendapat presentase (88\%). Begitu juga dengan jumlah indikator yang siswa ikuti pada proses belajar mengajar disiklus ke dua meningkat menjadi 20 item atau mendapat presentase (80\%). Ini menunjukan bahwa tindakan yang dilakukan disiklus kedua baik guru maupun siswa dapat dikatakan telah tuntas belajar. Berdasarkan hasil diatas maka disimpulkan bahwa dengan mengunakan media modifikasi dapat meningkatkan proses belajar mengajar teknik dasar lempar cakram.
\end{abstract}

Kata kunci : teknik dasar lempar cakram, proses belajar mengajar menggunakan media modifikasi.

\section{Abstract}

This research aims to improve the basic technique of the disc throwing in the learning process by using a modified media on students grade $5^{\text {th }}$ Elementary School Number 18 Bengkulu City. The type of this research is classroom action 
research. The subject of this research is student grade $5^{\text {th }}$ Elementary School Number 18 Bengkulu City which have 25 students inside. The result of pre-cycle in the class shows, the technique of disc throwing, overall there is 20 percent of the total students has been thoroughly studied and 80 percent of students hasnot been thoroughly studied. The results of this research, on first cycle show that just 18 items of all the items in observation sheet or 72 percents which teacher do on class, and just 13 items of all the items in student observation sheet or 52 percents which students do on class. It shows the class on category has not been thoroughly studied. While on second cycle show the total indicator which teacher do going into 22 items or 88 percent. The students also do better cause on second cycle total indicator which students do going into 20 items or 80 percent. It show that activity which do in the second cycle satisfaction. Based on result above, we can take conclusion modified media can increase teaching and learning process on class especially on disc throwing matery.

Keywords: Basic Technique of the Throwing, learning process by using a modified media

\section{PENDAHULUAN}

Atletik merupakan sarana untuk Pendidikan Jasmani dalam upaya meningkatkan kemampuan biomorik, misalnya kekuatan, daya tahan, kecepatan, kelenturan, koordinasi, dan sebagainya, menurut Feri Kurniawan (2012: 32). Pada cabang atletik khususnya nomor lempar cakram termasuk nomor yang sulit dilakukan karena di dalamnya mengandung unsur unsur gerak yang kompleks yang dimulai dari tahap persiapan, pelaksanaan, pemulihan.

Sarana dan prasarana merupakan salah satu bagian yang penting guna tercapainya tujuan pembelajaran. Oleh karena itu, sarana dan prasarana pembelajaran turut mempengaruhi maksimal dan tidak maksimalnya ketercapaian tujuan pembelajaran. Sarana yang lengkap bisa mempermudahkan guru dalam mengajar untuk mencapai targettarget tertentu yang menjadi tujuan pembelajaran. Begitupun sebaliknya, sarana yang tidak lengkap akan menyulitkan guru untuk mencapai target-target tujuan pembelajaran.

\begin{tabular}{llr}
\multicolumn{2}{c}{ Berdasarkan data yang } \\
diperoleh peneliti & saat \\
melasanakan magang 3 di SD
\end{tabular}
Negeri 18 Kota Bengkulu proses belajar mengajar lempar cakram masih sangat rendah hanya mendapatkan persenntase $20 \%$. Melihat kondisi tersebut menurut peneliti perlu adanya solusi yang tepat dalam menyikapi masalah proses pembelajaran penjas orkes, terutama pada materi ateltik cabang lempar cakram.

Melihat dari kondisi yang ada penggunaan media modifikasi alat merupakan salah satu karakteristik model pembelajaran yang dapat 
diterapkan. Dari penggunaan media modifikasi alat tersebut diharapkan proses pembelajaran teknik dasar lempar cakram pada peserta didik akan meningkat dan memiliki keterampilan yang beragam. Dari beberapa kriteria media alternatif modifikasi alat untuk meningkatkan teknik dasar lempar cakram tersebut nampaknya cakram yang terbuat dari kayu bisa dijadikan model pembelajaran media modifikasi untuk menggantikan cakram yang aslinya. Karena dari segi bentuk ada kemiripan dan media ini dapat dibuat sendiri.

Berdasarkan latar belakang yang telah diuraikan di atas ada beberapa masalah yang berkaitan dengan hasil belajar siswa. Adapun masalah tersebut yang dapat diidentifikasikan adalah sebagai berikut:
a. Proses belajar mengajar lempar cakram belum optimal di SD Negeri 18 Kota Bengkulu.
b. Rendahnya kereatifitas guru dalam merancang pembelajaran yang menarik.
c. Rendahnya pemahaman siswa dalam melakukan lempar cakram.
d. Kurangnya motivasi belajar siswa dalam berolahraga.
e. Terbatasnya sarana dan prasarana penunjang pembelajaran penjasorkes.

\begin{tabular}{|c|c|c|}
\hline Berdasa & ian & \\
\hline $\begin{array}{l}\text { asalah } \\
\text { batasi }\end{array}$ & $\begin{array}{l}\text { tas, } \\
\text { pada }\end{array}$ & \\
\hline eningkatk & & ose \\
\hline
\end{tabular}

Lempar Cakram dengan Menggunakan Media Modifikasi Pada Siswa Kelas V B SD Negeri 18 Kota Bengkulu Tahun Ajaran 2016/2017."

Pembelajaran adalah proses untuk membantu peserta didik agar dapat belajar dengan baik. Proses pembelajaran dialami sepanjang hayat seorang manusia serta dapat berlaku di manapun dan kapanpun. Guru mengajar supaya peserta didik dapat belajar dan menguasai isi pelajaran hingga mencapai sesuatu objektif yang ditentukan (aspek kognitif), dan juga mempengaruhi perubahan sikap (aspek afektif), serta keterampilan (aspek psikomotor) seorang pendidik.

Pengertian Lempar cakram, untuk memahami lempar cakram, terlebih dahulu kita memahami pengertian lempar dan cakram. Lempar adalah olahraga dengan melempar(lembing, peluru, martil, cakram). Sedangkan cakram sebuah benda berbantuk piring berbingkai sabuk besi. Jadi lempar cakram adalah salah satu nomor lomba dalam atletik yang mengunakan sebuah kayu yang berbentuk piring bersabuk besi, atau bahan lain yang bundar pipih yang dilemparkan.

Ada dua gaya dalam melempar cakram. Yang pertama gaya samping Sikap permulaan berdiri miring/menyamping kearah sasaran, sesaat akan memulai berputar lengan kanan diayun jauh ke belakang, sumbu putaran pada kaki kiri (telapak kaki bagian depan 
atau ujung) selama berputar lengan kanan selalu di belakang, pada posisi melempar badan merendah lengan kanan di belakang pandangan ke arah sasaran, setelah cakram lepas dari tangan kaki kanan melangkah ke depan berpijak dibekas telapak kaki kiri yang saat itu telah berayun ke belakang. Yang kedua gaya belakang, sikap pertama berdiri membelakangi arah lemparan sesaat akan berputar lengan kanan diayun jauh ke belakang pandangan mulai melirik ke kiri, saat mulai berputar ujung telapak kaki kiri sebagai sumbu dan tolakan kaki kiri itu pula badan meluncur ke arah lemparan, kaki kanan secepatnya diayunkan memutar ke kiri untuk berpijak, sesaat kaki kanan mendarat kaki kiri dengan cepat pula diayunkan ke kiri untuk berpijak dan terjadilah sikap lempar,setelah cakram lepas dari tangan kaki kanan segera diayun ke depan dan kaki kiri diayun ke belakang.

\section{METODE}

Jenis penelitian ini merupakan penelitian tindakan kelas (PTK). Prosedur atau langkahlangkah penelitian yang dilakukan terbagi dalam bentuk siklus kegiatan, mengacu pada model yang diadopi dari hopkins (1993: 43) dalam Kunandar, di mana setiap setiap siklus terdiri dari atas empat kegiatan pokok adalah kegiatan perencanaan, tindakan, observasi, dan refleksi. Dalam penelitian ini yang menjadi subjek penelitian adalah siswa kelas $\mathrm{V} B$ SD Negeri 18 Kota Bengkulu, yang berjumlah 25 siswa.Waktu Pelaksanaan penelitian akan dimulai di semester II tahun pelajaran 2016/2017.

\section{HASIL}

Penelitian tindakan kelas ini dilaksanakan dalam dua siklus. Hasil penelitian pada tiap-tiap siklus dideskripsikan sebagai berikut:

1. Siklus Ke Satu

a. Pendahuluan

Pada siklus pertama kegiatan pendahuluan peneliti memberikan materi atletik cabang lempar cakram yang dilakukan pada hari rabu tanggal 29 maret 2017 dimulai pukul 08.00 sampai pukul 09.15 WIB. Kegiatan pendahuluan dilaksanakan selama 15 menit, setelah bel berbunyi siswa kelas $\checkmark$ B telah mempersiapkan diri di lapangan. Guru selanjutnya mengkondisikan siswa untuk menerima pelajaran, kemudian melakukan berdoa dan mengecek kehadiran siswa.Setelah itu guru melakukan apersepsi dengan mendeskripsikan teknik dasar lempar cakram dan menjelaskan media yang akan digunakan. Selesai melakukan apersepsi dan tanya jawab, guru menyampaikan tujuan pembelajaran yang akan dicapai siswa yaitu melakukan kegiatan lempar cakram. Kemudian guru memberikan materi pemanasan 
sebelum masuk ke dalam kegiatan inti.

b. Kegiatan Inti/Tindakan

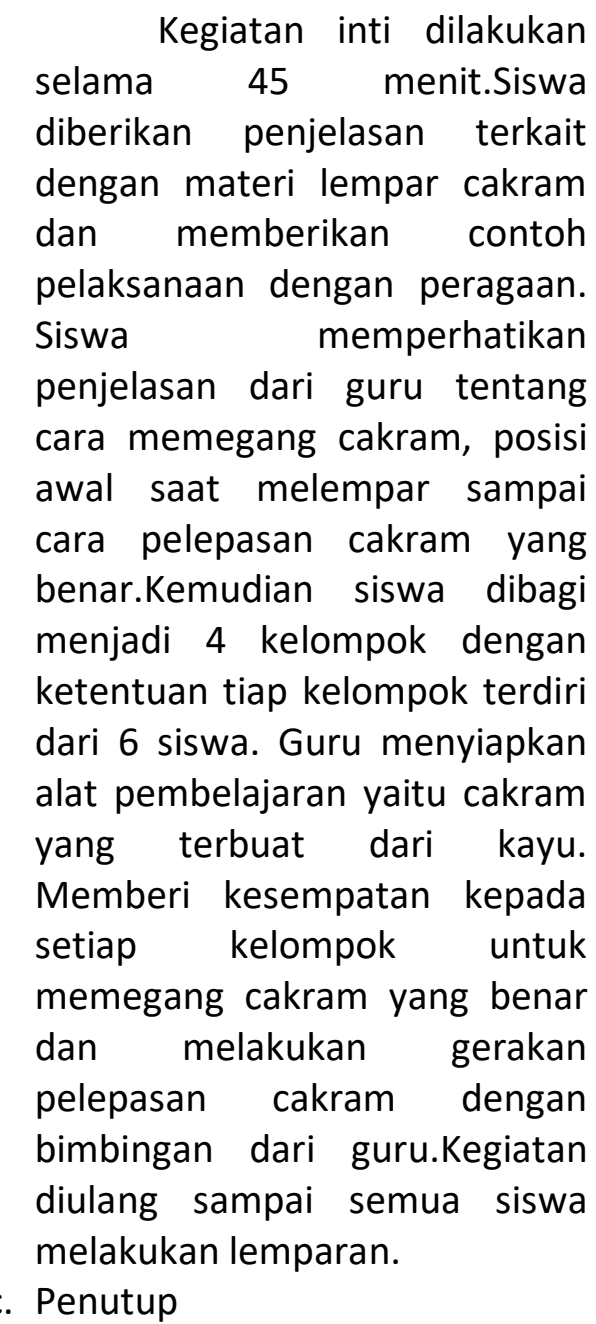

Kegiatan

akhir

dilaksanakan selama 10 menit, pada kegiatan akhir guru mengkondisikan siswa kembali dengan tertib dan rapi, kemudian guru bersama-sama dengan siswa melakukan gerakan pendinginan.Setelah selesai melaksanakan pendinginan, guru melakukan tanya jawab tentang materi yang telah diberikan yaitu lempar cakram, guru menanyakan apakah masih ada siswa yang belum paham mengenai materi yang baru saja dipelajari oleh siswa kemudian guru menanggapi permasalahan yang dialami oleh siswa dan diakhiri kegiatan guru menyimpulkan pembelajaran lalu menutup pembelajaran dengan berdoa bersama-sama dan dibubarkan.

Dari hasil diskusi yang telah dilakukan peneliti bersama teman sejawat pada tindakan disiklus ke satu dapat disimpulkan bahwa, proses belajar mengajar teknik dasar lempar cakram dengan mengunakan media modifikasi cakram yang terbuat dari kayu pada siswa kelas $\mathrm{V}$ B di SD Negeri 18 Kota Bengkulu belum memenuhi kriteria ketuntasan minimal (KKM), dapat dilihat dari jumlah indikator pada lembar observasi aktivitas guru dalam pembelajaran masih terlaksana 18 item atau baru mendapat presentase (72\%), dan pada lembar observasi aktivitas belajar siswa pada pembelajaran masih terlaksana 13 item atau baru mendapat presentase (52\%) dari jumlah keseluruhan lembar observasi yaitu 25 item. Ini menunjukan bahwa proses belajar mengajar baik guru maupun siswa masih rendah atau masih pada kategori belum tuntas belajar. Sehingga perlu adanya tindakan ke siklus kedua karena berdasarkan indikator pencapaian nilai standar kriteria 
ketuntasan minimal (KKM) dapat dinyatakan tuntas belajar jika proses belajar mengajar baik guru maupun siswa mencapai presentase (75\%).

Gambar 22. Diagram Nilai Lembar Observasi Siklus Kesatu

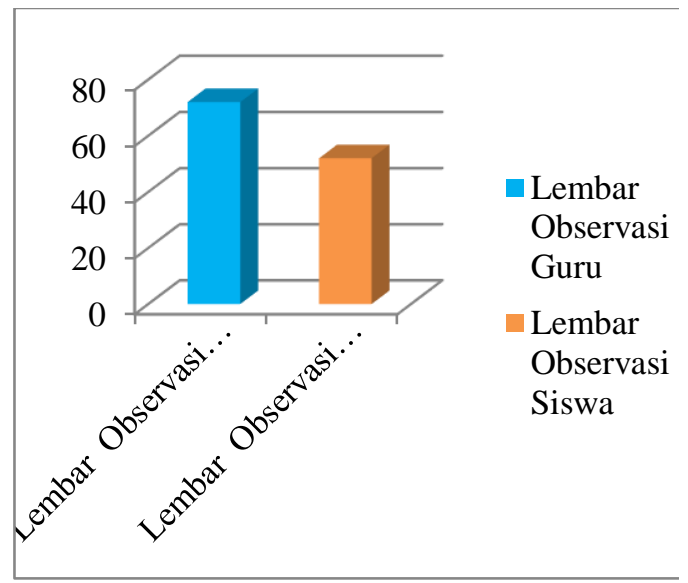

Berdasarkan diagram di atas menunjukan bahwa proses belajar mengajar teknik dasar lempar cakram dengan menggunakan media modifikasi pada siklus kesatu belum tuntas belajar atau belum mencapai standar indikator keberhasilan yang ditetapkan yaitu (75\%).

2. Siklus KeDua

a. Pendahuluan

Pada tindakan disiklus kedua kegiatan penelitian dilakukan pada hari rabu tanggal 05 april 2017, pembelajaran penjas orkes dengan materi atletik cabang lempar cakram dimulai pada pukul 08.00 sampai 09.15 WIB. Setelah bel berbunyi siswa kelas $V \quad B$ berkumpul di lapangan.Pelaksanaan pembelajaran diawal kegiatan pendahuluan dengan waktu selama 15 menit.Guru yang telah hadir di lapangan mengkondisikan siswa untuk berbaris dengan tertib dan rapi. Untuk mengawali dimulainya pembelajaran guru bersamasama dengan siswa melakukan doa, setelah berdoa guru melakukan sapa salam dan dilanjutkan dengan mengecek kehadiran siswanya,Selesai mengecek kehadiran siswa, guru melakukan apersepsi dan menyampaikan tujuan dalam mengikuti proses belajar mengajar lempar cakram. Kemudian sebelum masuk kegiatan inti guru memimpin pada pemanasan yang dilakukan dan diikut bersama-sama dengan siswanya.

\section{b. Kegiatan Inti/tindakan}

Pada kegiatan inti dilakukan selama 45 menit, kegiatan diawali dengan guru memberikan penjelasan kepada siswa tentang materi lempar cakram, mendemonstrasikan cara memegang cakram dengan cakram yang terbuat dari kayu secara benar, terlihat siswa antusias mendengarkan penjelasan dan siswa ikut meragakan apa yang dicontohkan oleh guru pada saat melakukan posisi awal, gerakan awal, saat melakukan putaran sampai gerakan pelepasan dalam melempar cakram.Kemudian guru membagi siswa menjadi perkelompok dengan ketentuan setiap kelompok nantinya maju 
satu per satu untuk melakukan gerakan keseluruhan melempar cakram dengan cara bergantian setiap kelompoknya. Kegiatan dilakukan dengan didampingi oleh guru pengajar agar pada saat ada siswa yang mengalami kesulitan saat melakukan lemparan guru langsung bertindak memberikan arahan supaya siswa dapat melakukan lemparan cakram dengan teknik yang benar.Kegiatan dilakukan sampai semua siswa dapat melakukan lemparan.

c. Penutup

Pelaksanaan kegiatan akhir selama 10 menit, guru mengkondisikan siswa kembali untuk berbaris dengan tertib dan rapi, kemudian guru bersama-sama dengan siswa melakukan pendinginan,Setelah selesai melakukan pendinginan, guru memberikan arahan dan menanyakan kepada siswanya apakah sudah paham mengenai materi lempar cakram yang sudah bersama-sama dipelajari, diakhir pembelajaran guru menyimpulkan pembelajaran yang telah dilakukan selama proses belajar mengajar dan bersama-sama dengan siswa melakukan perbaikan apa yang salah pada saat melakukan gerakan melempar cakram, guru menutup memberikan pesan agar siswa rajin berlatih dan menutup pembelajaran dengan berdoa bersama-sama siswa dan dibubarkan
Berdasarkan hasil diskusi peneliti dengan teman sejawat lakukan bahwa tindakan disiklus ke dua pada pelaksanaan proses belajar mengajar lempar cakram dengan menggunakan media modifikasi pada siswa kelas $\mathrm{V} B$ di SD Negeri 18 Kota Bengkulu sudah terlaksana dengan baik dan mengalami perubahan peningkatan dibandingkan dengan proses belajar mengajar disiklus ke satu. Peningkatan proses belajar mengajar itu dapat dilihat pada lembar observasi baik guru maupun siswa. Jumlah indikator yang guru lakukan pada proses belajar mengajar disiklus ke dua yaitu 22 item atau mendapat presentase $(88 \%)$ telah tuntas belajar dibandingkan pada siklus ke satu yang terlaksana 18 item atau mendapat presentase (72\%) belum tuntas belajar. Begitu juga dengan jumlah indikator yang siswa ikuti pada proses belajar mengajar disiklus ke dua yaitu 20 item atau mendapat presentase (80\%) telah tuntas belajar dibandingkan pada siklus ke satu indikator yang terlaksana 13 item atau mendapat presentase $(52 \%)$ belum tuntas belajar. Berdasarkan hasil tersebut maka dapat disimpulkan bahwa penelitian ini telah mencapai standar indikator keberhasilan yang ditetapkan yaitu (75\%).

Gambar 32. Diagram Nilai Lembar Observasi Siklus Kedua 


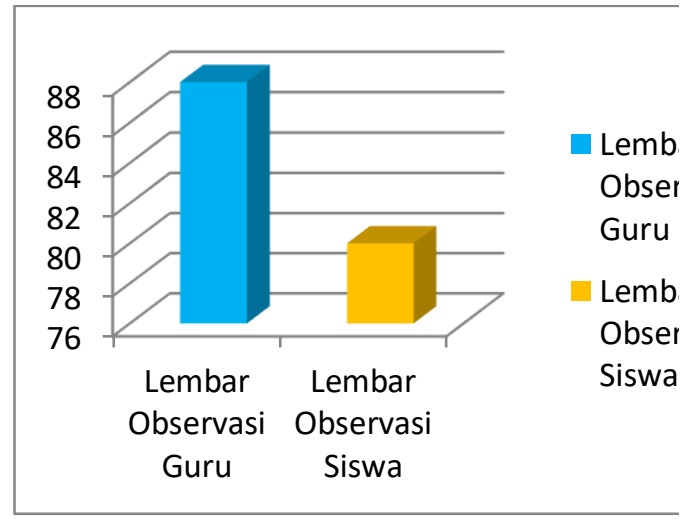

Berdasarkan diagram di atas menunjukan bahwa proses belajar mengajar teknik dasar lempar cakram dengan menggunakan media modifikasi pada siklus kedua tuntas belajar atau telah mencapai standar indikator keberhasilan yang ditetapkan yaitu (75\%).

\section{HASIL DAN PEMBAHASAN \\ Hasil}

Penelitian Tindakan Kelas (PTK) meliputi 2 siklus yang terdiri dari siklus I dan siklus II.Setiap siklus teridiri beberapa tahap, yaitu tahap pendahuluan, kegiatan inti, penutup, refleksi, revisi/perbaikan dan kesimpulan.Hasil yang diperoleh pada penelitian ini terdiri dari data observasi aktivitas pembelajaran baik guru maupun siswa yang diperoleh melalui pembelajaran Pendidikan Jasmani Kesehatan dengan materi lempar cakram yang medianya dimodifikasi menggunakan cakram yang terbuat dari kayu.Hasil dari ke dua siklus tersebut digunakan untuk mengetahui peningkatan ketuntasan belajar baik guru maupun siswa dengan modifikasi media pembelajaran pendidikan jasmani kesehatan materi lempar cakram pada siswa kelas V B SD Negeri 18 Kota Bengkulu.

Hasil disiklus ke satu menunjukan bahwa jumlah indikator pada lembar observasi aktivitas guru dalam pembelajaran masih terlaksana 18 item atau baru mendapat presentase (72\%), dari jumlah indikator 25 item.Dan untuk lembar observasi aktivitas belajar siswa pada pembelajaran masih terlaksana 13 item atau baru mendapat presentase (52\%) dari jumlah keseluruhan lembar observasi yaitu 25 item. Ini menunjukan bahwa proses belajar mengajar baik guru maupun siswa masih rendah atau masih pada kategori belum tuntas belajar karena belum mencapai indikator yang ditetapkan yaitu (75\%).

Kemudian hasil disiklus ke dua menunjukan bahwa jumlah indikator yang guru lakukan pada proses belajar mengajar meningkat yaitu 22 item atau mendapat presentase (88\%), dibandingkan tindakan disiklus satu hanya mendapat presentase (72\%). Begitu juga dengan jumlah indikator yang siswa ikuti pada proses belajar mengajar disiklus ke dua meningkat menjadi 20 item atau mendapat presentase (80\%), dibandingkan tindakan disiklus kesatu hanya mendapat (52\%). Ini menunjukan bahwa tindakan yang dilakukan disiklus kedua baik guru maupun siswa dapat dikatakan telah tuntas belajar dibandingkan pada siklus ke satu.Berdasarkan hasil tersebut maka dapat disimpulkan bahwa penelitian ini telah mencapai 
standar indikator keberhasilan yang ditetapkan yaitu (75\%).

\section{PENUTUP}

\section{Simpulan}

Berdasarkan data dari hasil penelitian, serta sesuai dengan permasalahan dan pembahasan dalam penelitian tindakan kelas dengan 2 siklus atau 2 kali tatap muka yang dilakukan peneliti dapat disimpulkan bahwa dengan media modifikasi dapat meningkatkan teknik dasar lempar ckaram dalam proses belajar mengajar pada siswa kelas V B SD Negeri 18 Kota Bengkulu. Hal ini dapat dilihat dari perbandingan hasil evaluasi siklus satu dan disiklus kedua mengalami peningkatan dalam proses belajar. Pada lembar observasi aktifitas guru proses belajar mengajar dari jumlah indikator keseluruhan 25 item pada siklus 1 terlaksana 18 item atau baru mendapat presentase (72\%) pada tindakan disiklus kedua meningkat menjadi 22 item atau (88\%). Begitu juga pada lembar observasi aktifitas siswa dalam mengikuti proses belajar mengajar dari jumlah indikator 25 item pada siklus 1 terlaksana 13 item atau baru mendapat presentase (52\%) pada siklus kedua meningkat menjadi 20 item atau (80\%). Ini menunjukan bahwa peran media modifikasi mampu memberikan perubahan dan memudahkan siswa dalam menerima materi dan menerima konsep yang benar dalam proses belajar mengajar teknik dasar lempar cakram.

\section{Saran}

Saran-saran yang dapat
dijadikan sebagai bahan
pertimbangan untuk peningkatan
proses belajar mengajar pendidikan
jasmani setelah dilakukan penelitian
ini yaitu:

1. Bagi sekolah

Perlu adanya penyediaan fasilitas sarana dan prasarana untuk pengajaran pendidikan jasmani yang lebih lengkap oleh sekolah

2. Bagi guru

Guru-guru pendidikan jasmani sebaiknya dapat menerapkan pembelajaran pendidikan jasmani dengan variasi-variasi pembelajaran untuk mengatasi kesulitan penafsiran gerak komplek oleh siswa.

3. Bagi siswa

Siswa hendaknya

membiasakan diri untuk belajar mengunakan berbagai macam variasi pembelajaran, sehingga akan terbiasa dan hasil pembelajaran yang diperoleh akan meningkat.

4. Bagi peneliti lain

Hasil penelitian ini dapat digunakan sebagai pengembangan pada penelitian berikutnya dengan materi dan media lainya.

\section{DAFTAR PUSTAKA}

Feri Kurniawan. (2012). Buku Pintar Pengetahuan Olahraga. Jakarta: Laskar Aksara. 


\author{
Kunandar.(2013). Langkah \\ Mudah Penelitian \\ Tindakan Kelas. Jakarta: \\ PT Raja Grafindo
}

Nuryati, Arwin, dan Bogy. 2017.

"Upaya Peningkatan

Proses Belajar Atletik

Tolak Peluru Melalui

Penerapan Media POA

Pada Siswa Kelas V SD

Negeri $05 \quad$ Kota

Bengkulu".Jurnal

Kinestetik, Vol. 1 (2).

Tangkudung, James. (2012). Kepelatihan Olahraga

Pembinaan Prestasi

Olahraga. Jakarta:

Cerdas jaya

,(2016).Macam-macam

Metodologi Penelitian.

Jakarta: Lensa Media

Pustaka Indonesia 